\title{
Exogenous BMP9 promotes lung fibroblast HFL-1 cell activation via ALK1/Smad1/5 signaling in vitro
}

\author{
YAQUN WANG ${ }^{1,2}$, XIAONAN SIMA ${ }^{3}$, YING YING ${ }^{1}$ and YONGHONG HUANG ${ }^{1}$ \\ ${ }^{1}$ Department of Pathophysiology, Basic Medical College, Nanchang University; \\ ${ }^{2}$ Graduate College, Nanchang University, Nanchang, Jiangxi 330006; ${ }^{3}$ Nanchang Joint Program, \\ Queen Mary School, Nanchang University, Nanchang, Jiangxi 330031, P.R. China
}

Received February 28, 2020; Accepted June 24, 2020

DOI: $10.3892 / \mathrm{etm} .2021 .10160$

\begin{abstract}
Bone morphogenetic protein 9 (BMP9) has recently been described as a crucial regulator in modulating fibroblasttype cell activation. Activin receptor-like kinase 1 (ALK1) is a high affinity receptor for BMP9 that exerts its role via Smad1/5. However, the functional roles of BMP9 in activating lung fibroblasts and the underlying signaling pathway are not completely understood. The present study aimed to explore the effect of exogenous BMP9 on human lung fibroblast HFL-1 cell proliferation and differentiation, as well as the potential role of the ALK1/Smad1/5 signaling pathway. In the present study, fibroblast proliferation was assessed using Cell Counting Kit- 8 and colony formation assays, and the mRNA and protein expression of target genes was examined using reverse transcription-quantitative PCR and western blot assays, respectively. Compared with the control group, BMP9 treatment increased HFL-1 cell proliferation, mRNA and protein expression of differentiated markers, including $\alpha$-smooth muscle actin, type I collagen and type III collagen, and the expression of ALK1 and phosphorylated Smad1/5 expression. Furthermore, the effects of BMP9 were partially rescued by dorsomorphin-1, an inhibitor of ALK1. The results indicated that BMP9 may serve as a key inducer of lung fibroblast activation and ALK1/Smad1/5 signaling might be associated with BMP9-mediated effects in HFL-1 cells. Therefore, the present study highlighted that the potential role of the BMP9/ALK1/ Smad1/5 signaling pathway in the development of pulmonary fibrosis requires further investigation.
\end{abstract}

Correspondence to: Professor Yonghong Huang, Department of Pathophysiology, Basic Medical College, Nanchang University, 462 Bayi Road, Nanchang, Jiangxi 330006, P.R. China E-mail: yhhuang0710@163.com

Key words: bone morphogenic protein 9, activin receptor-like kinase 1, proliferation, differentiation, lung fibroblast, signaling pathway, in vitro

\section{Introduction}

Pulmonary fibrosis is a chronic interstitial lung disease that can destroy the normal architecture of lung tissues and lead to progressive respiratory dysfunction (1). Fibroblasts are the major effector cells during pulmonary fibrosis due to their ability to differentiate into myofibroblasts, which can synthesize excess extracellular matrix (ECM) proteins, resulting in excessive ECM deposition and pulmonary fibrosis (2). The key difference between quiescent fibroblasts and activated fibroblasts (myofibroblasts) manifests as aberrant proliferative capacity and increased production of $\alpha$-smooth muscle actin ( $\alpha$-SMA) and ECM proteins, such as type I collagen (collagen I), type III collagen (collagen III), connective tissue growth factor (CTGF) and fibronectin, when fibroblasts are activated (3). Therefore, targeting fibroblast activation may serve as a therapeutic strategy for pulmonary fibrosis.

The transforming growth factor $\beta$ (TGF- $\beta$ ) family, including TGF- $\beta$, bone morphogenetic proteins (BMPs) and activins, is involved in the development of fibrotic diseases (4-6). TGF- $\beta 1$ is widely considered as the primary cytokine responsible for the induction of fibroblast activation (7); however, the precise functions of other BMPs, such as BMP9, in activating fibroblasts and fibrosis development are not completely understood.

BMP9 was originally identified in liver tissues and considered as an important participant of several biological functions, including hepatocyte proliferation, chondrogenesis, angiogenesis, glucose metabolism and neuronal differentiation (8-12). BMP9 primarily binds to its high affinity receptor activin receptor-like kinase 1 (ALK1) to phosphorylate Smad1/5 and regulate gene transcription $(13,14)$. In addition, non-Smad signaling proteins, such as mitogen-activated protein kinases, PI3K and c-met, can also be activated by BMP9 $(15,16)$. The BMP9/ALK1 signaling pathway is involved in the angiogenesis and metastasis of tumors (17-19). For instance, exogenous BMP9 can significantly inhibit breast cancer MDA-MB-231 cell invasion and migration in vitro and in vivo (19). However, BMP9 is overexpressed in hepatocellular carcinoma tissues, and can induce epithelial-mesenchymal transition and promote hepatocellular carcinoma metastasis (20). BMP9 also induces proliferation in multiple types of endothelial cells in vitro and promotes tumor angiogenesis and metastasis in a xenograft model of pancreatic cancer (21). 
It has been reported that BMP9 is a vital cytokine that regulates the activation of fibroblasts and development of fibrosis $(9,22-26)$. Increasing studies have indicated that BMP9 has a bidirectional response to fibroblast activation and fibrotic diseases (9,22-26). Breitkopf-Heinlein et al (9) indicated that BMP9 serves as a profibrogenic cytokine in hepatic tissues. Selective inhibition or deletion of BMP9 in mice results in reduced liver fibrosis compared with the control group, and BMP9 overexpression promotes hepatic stellate cell proliferation and migration, which are the major fibroblast-type cells involved in hepatic fibrosis (9). Moreover, Li et al (22) demonstrated a positive correlation between serum levels of BMP9 and the stage of fibrosis in 52 patients, suggesting that BMP9 might serve as an early diagnostic marker for hepatic fibrosis (22). BMP9 also stimulates mouse embryo fibroblast activation and increases the expression of fibronectin and collagen I by triggering Smad1/5 signaling (23). By contrast, other studies have identified an inhibitory role of BMP9 and its receptor ALK1 during fibrogenesis. For instance, Morine et al (24) observed that BMP9 is expressed by cardiac fibroblasts, but its expression is upregulated in the circulation and left ventricle of human patients with heart failure (24). Furthermore, BMP9 decreases the synthesis of collagen I in cardiac fibroblasts, and loss of BMP9 activity increases cardiac fibrosis by inhibiting Smad1 phosphorylation (24). Meanwhile, ALK1 has been reported to suppress cardiac fibrosis by maintaining Smad1 activity in a mouse model of heart failure (25). Moreover, reduced levels of ALK1 have also been reported to accelerate heart failure without increasing markers of cardiac fibrosis, such as collagen I, CTGF or plasminogen activator inhibitor 1 (26). Therefore, the contribution of BMP9 to fibroblast activation and fibrogenesis requires further investigation. Certain strategies targeting BMP9 have been applied in the preclinical treatment of fibrotic diseases and have displayed positive effects $(9,16,22,27)$. For example, mice treated with BMP9short hairpin RNA and monoclonal antibodies display limited liver fibrosis (27).

At present, there is no direct evidence that BMP9 regulates pulmonary fibrosis. However, several studies have indicated that BMP9 serves a pivotal role in several chronic lung diseases related to fibrosis, such as bronchopulmonary dysplasia and pulmonary arterial hypertension $(28,29)$. In the present study, the role of BMP9 in regulating human lung fibroblast proliferation and differentiation, as well as underlying signaling pathway, were investigated.

\section{Materials and methods}

Cell culture. Human fetal lung fibroblasts HFL-1 (The Cell Bank of Type Culture Collection of the Chinese Academy of Sciences) were cultured in DMEM (HyClone; Cytiva) supplemented with 6\% FBS (HyClone; Cytiva) and penicillin/ streptomycin solution (Beijing Solarbio Science \& Technology Co., Ltd.) at $37^{\circ} \mathrm{C}$ in a humidified incubator with $5 \% \mathrm{CO}_{2}$. Cells in the exponential growth phase were used for subsequent experiments. For the experiment of rBMP9 treatment, DMEM without rBMP9 is used as control. For the experiment of rBMP9 combined with dorsomorphin-1 (Dor), DMEM with $0.1 \%$ dimethyl sulfoxide is used as control.
Table I. Sequences of the primers used for reverse transcription-quantitative PCR.

\begin{tabular}{ll}
\hline Gene & \multicolumn{1}{c}{ Sequence (5'-3') } \\
\hline$\alpha$-SMA & F: AGCGTGGCTATTCCTTCGT \\
& R: CTCATTTTCAAAGTCCAGAGCTACA \\
Collagen I & F: AACCAAGGCTGCAACCTGGA \\
& R: GGCTGAGTAGGGTACACGCAGG \\
Collagen III & F: CTCCTGGGATTAATGGTAGT \\
& R: CCAGGAGCTCCAGGAAT \\
GAPDH & F: AGAAGGCTGGGGCTCATTTG \\
& R: AGGGGCCATCCACAGTCTTC
\end{tabular}

$\alpha$-SMA, $\alpha$-smooth muscle actin; F, forward; R, reverse.

Cell viability assay. A Cell Counting Kit-8 (CCK-8) assay (Beijing Transgen Biotech Co., Ltd.) was used to detect cell viability. Briefly, HFL-1 cells $\left(1 \times 10^{3}\right)$ were cultured in a 96-well plate for $24 \mathrm{~h}$ and starved in DMEM with $0.1 \%$ FBS at $37^{\circ}$ Covernight. Subsequently, cells were treated with fresh DMEM containing: i) Different concentrations of recombinant BMP9 (rBMP9; 0, 2, 10 or $50 \mathrm{ng} / \mathrm{ml}$; BioLegend, Inc.) at $37^{\circ} \mathrm{C}$ for 24,48 or $72 \mathrm{~h}$; or ii) $50 \mathrm{ng} / \mathrm{ml} \mathrm{rBMP9}$ with different concentration of Dor $(0,0.1,0.5$ or $1 \mu \mathrm{M}$; MedChemExpress LLC), a BMP type I receptor ALK1 inhibitor, at $37^{\circ} \mathrm{C}$ for $48 \mathrm{~h}$. Subsequently, $10 \mu \mathrm{l}$ CCK-8 solution was added to each well. After incubation at $37^{\circ} \mathrm{C}$ for $30 \mathrm{~min}$, the absorbance of each well was measured at a wavelength of $450 \mathrm{~nm}$ using a multi-mode microplate reader (Molecular Devices, LLC). The absorbance value recorded was directly proportional to the number of viable cells.

Colony formation assay. Briefly, HFL-1 cells $\left(1 \times 10^{3}\right)$ were subcultured in $6-\mathrm{cm}$ dishes at $37^{\circ} \mathrm{C}$ for $24 \mathrm{~h}$. Subsequently, cells were treated with fresh DMEM containing different concentrations of $\mathrm{rBMP} 9(0,2,10 \mathrm{or} 50 \mathrm{ng} / \mathrm{ml})$ in the presence or absence of $0.1 \mu \mathrm{M}$ Dor at $37^{\circ} \mathrm{C}$. The culture medium was replaced every 3 days. Following incubation for 10 days, cells were fixed with $4 \%$ paraformaldehyde at room temperature for 20 min and stained with $1 \%$ crystal violet (Beijing Solarbio Science \& Technology Co., Ltd.) at room temperature for $15 \mathrm{~min}$. The images of 6-cm dish were obtained by Scanner. The number of colonies (the cell clusters $>0.5 \mathrm{~mm}$ is defined as a colony) in each $6-\mathrm{cm}$ dish was calculated using Image J software (version 1.80; National Institutes of Health).

Reverse transcription-quantitative PCR (RT-qPCR). Following incubation with $50 \mathrm{ng} / \mathrm{ml} \mathrm{rBMP} 9$ and/or $0.1 \mu \mathrm{M}$ Dor for 48 h, HFL-1 cells $\left(5 \times 10^{6}\right)$ in a 6 -cm dish were washed twice with ice-cold PBS. Total RNA was extracted from cells using TRIzol ${ }^{\circledR}$ reagent (Beijing Transgen Biotech Co., Ltd.) according to the manufacturer's protocol. Total RNA was reverse transcribed to cDNA using the Reverse Transcription System (cat. no. A3500; Promega Corporation). The temperature protocol for reverse transcription was $42^{\circ} \mathrm{C}$ for $15 \mathrm{~min}$, $95^{\circ} \mathrm{C}$ for $5 \mathrm{~min}$ and $4^{\circ} \mathrm{C}$ for $5 \mathrm{~min}$. Subsequently, qPCR was 

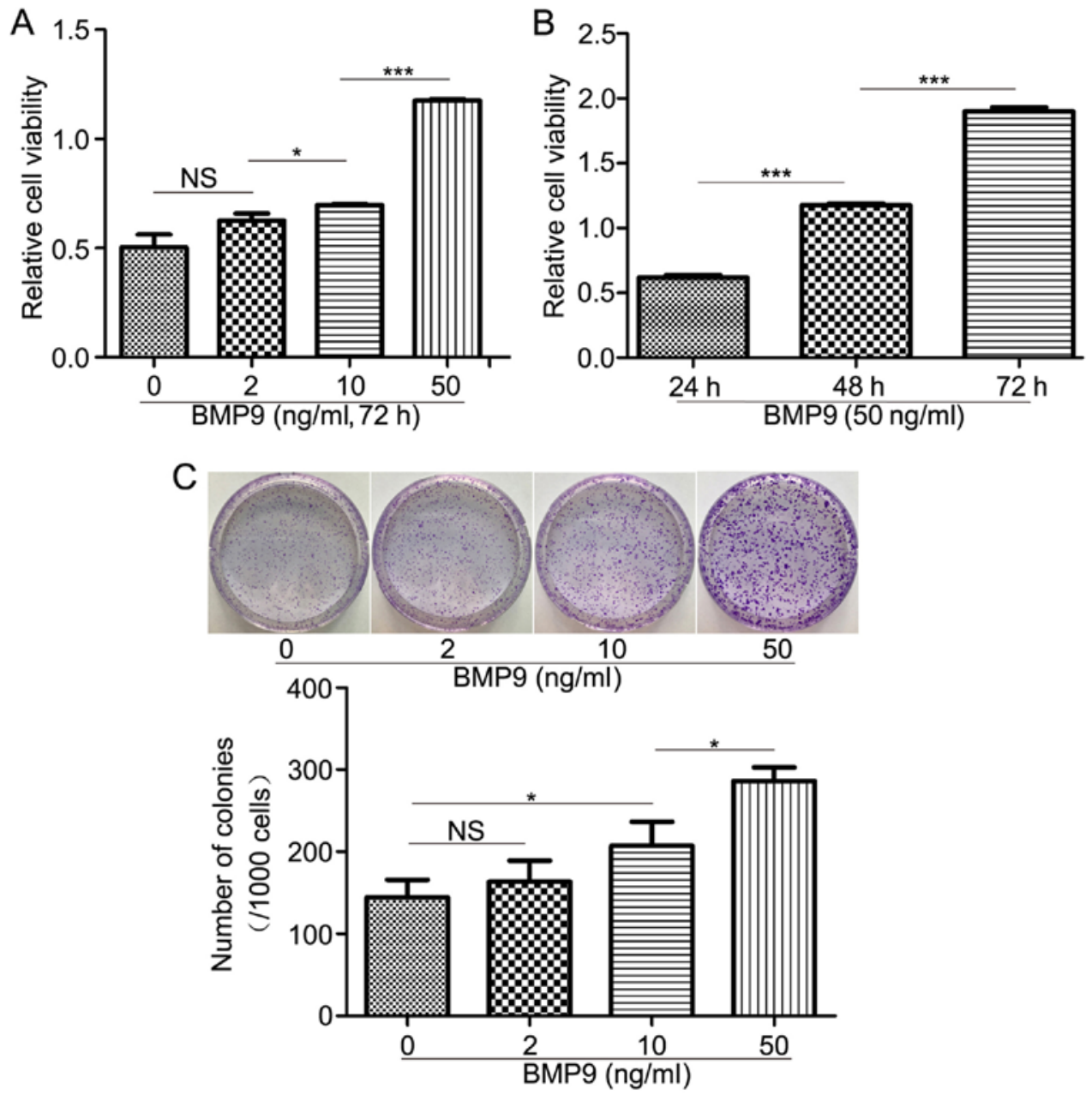

Figure 1. BMP9 promotes HFL-1 cell proliferation. HFL-1 cells were incubated with (A) different concentrations of BMP9 or (B) $50 \mathrm{ng} / \mathrm{ml}$ BMP9 for different incubation periods. (C) Effect of BMP9 on HFL-1 cell colony formation. ${ }^{*} \mathrm{P}<0.05$ and ${ }^{* * *} \mathrm{P}<0.001$. BMP9, bone morphogenetic protein 9; NS, not significant.

performed using the SYBR Green kit (Beijing Transgen Biotech Co., Ltd.) and an ABI Prism 7500 Sequence Detection System (Applied Biosystems; Thermo Fisher Scientific, Inc.). The following thermocycling conditions were used for qPCR: Initial denaturation for $10 \mathrm{~min}$ at $95^{\circ} \mathrm{C}$; followed by 35 cycles of denaturation at $95^{\circ} \mathrm{C}$ for $15 \mathrm{sec}$, annealing at $60^{\circ} \mathrm{C}$ for $30 \mathrm{sec}$ and extension at $72^{\circ} \mathrm{C}$ for $10 \mathrm{sec}$. The sequences of the primers used for qPCR are listed in Table I. mRNA expression levels were quantified using the $2^{-\Delta \Delta C q}$ method (30) and normalized to the internal reference gene GAPDH.

Western blotting. Briefly, HFL-1 cells $\left(5 \times 10^{6}\right)$ were cultured in 6 -cm dish with different concentrations of rBMP9 $(0,2,10$ or $50 \mathrm{ng} / \mathrm{ml}$ ) or $0.5 \mu \mathrm{M}$ Dor at $37^{\circ} \mathrm{C}$ for 24 or $48 \mathrm{~h}$. Cells were then washed twice with ice-cold PBS. Total protein was extracted from cells using RIPA lysis buffer (cat. no. P0013B; Beyotime Institute of Biotechnology) on ice. Cell debris was discarded by centrifugation at $12,000 \mathrm{x}$ g at $4^{\circ} \mathrm{C}$ for $5 \mathrm{~min}$. Total protein was quantified using a Bicinchoninic Acid Protein Assay kit (cat. no. P0010; Beyotime Institute of Biotechnology). Proteins (40 $\mu \mathrm{g} / \mathrm{lane})$ were separated via $8-10 \%$ SDS-PAGE and transferred to nitrocellulose membranes (EMD Millipore). The membranes were blocked with 5\% non-fat milk for $1 \mathrm{~h}$ at room temperature. Subsequently, the membranes were incubated overnight at $4^{\circ} \mathrm{C}$ with primary antibodies targeted against: ALK1 (1:500; cat. no. DF3170; Affinity Biosciences), collagen I (1:500; cat. no. AF7001; Affinity Biosciences), collagen III (1:500; cat. no. AF5457; Affinity Biosciences), $\alpha$-SMA (1:1,000; cat. no. ab124964; Abcam), phosphorylated (p)-Smad1/5 (1:1,000; cat. no. CST9516; Cell Signaling Technology, Inc.), total-Smad1/5 (1:1,000; cat. no. CST6944; Cell Signaling Technology, Inc.) and GAPDH $(1: 1,000$; cat. no. T0004; Affinity Biosciences). Following primary incubation, the membranes were incubated with horseradish peroxidase-conjugated secondary antibodies (1:5,000; cat. nos. S0001 and S0002; Affinity Biosciences) for $2 \mathrm{~h}$ at room temperature. Protein bands were visualized using an enhanced chemiluminescence kit (EMD Millipore). Protein expression was quantified using ImageJ software (version 1.80; National Institutes of Health) with GAPDH as the loading control (31).

Statistical analysis. Data are presented as the mean \pm standard deviation from at least three independent experiments. Statistical analyses were performed using GraphPad Prism software (version 5; GraphPad Software, Inc.). Comparisons between two groups were analyzed using the unpaired Student's t-test. Comparisons among multiple groups were analyzed using one-way ANOVA followed by Tukey's post hoc 


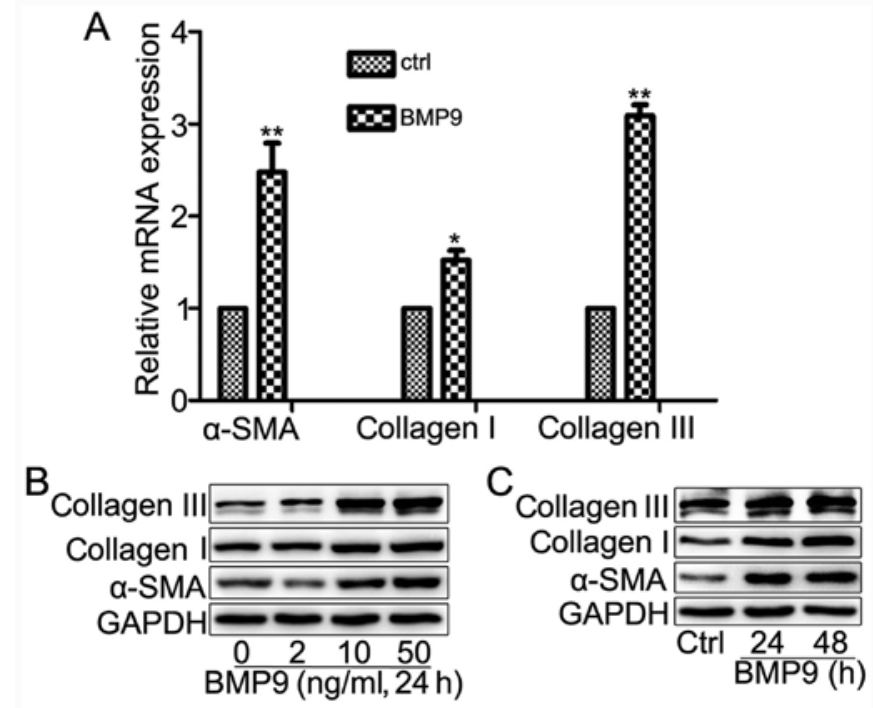

Figure 2. BMP9 increases HFL-1 cell transdifferentiation. (A) mRNA expression levels of $\alpha$-SMA, collagen I and collagen III. Effect of (B) different concentrations of BMP9 and (C) incubation with BMP9 for different time periods on the protein expression levels of $\alpha$-SMA, collagen I and collagen III. ${ }^{*} \mathrm{P}<0.05$ and ${ }^{* *} \mathrm{P}<0.01$ vs. ctrl. BMP9, bone morphogenetic protein 9; $\alpha$-SMA, $\alpha$-smooth muscle actin; ctrl, control.

test. $\mathrm{P}<0.05$ was considered to indicate a statistically significant difference.

\section{Results}

BMP9 increases HFL-1 cell proliferation. Abnormal proliferation is a characteristic of lung fibroblast activation (32). Therefore, to determine whether BMP9 altered the proliferation of HFL-1 cells, the CCK-8 assay was performed to assess HFL-1 cell proliferation following treatment with BMP9. BMP9 enhanced HFL-1 cell proliferation in a concentration- and time-dependent manner (Fig. 1A and B). Similarly, the colony formation assay suggested that BMP9 increased colony formation in a dosedependent manner (Fig. 1C). The results indicated that BMP9 stimulation promoted HFL-1 cell proliferation.

BMP9 induces HFL-1 cell differentiation. To investigate whether BMP9 served an important role in lung fibroblast activation, the effect of BMP9 on HFL-1 cell transdifferentiation was investigated. Firstly, the mRNA expression levels of myofibroblast marker $\alpha$-SMA, and ECM markers collagen I and collagen III were assessed. The results indicated that BMP9 significantly increased the expression levels of $\alpha$-SMA, collagen I and collagen III in HFL-1 cells compared with the control group (Fig. 2A). Furthermore, the protein expression levels of collagen I, collagen III and $\alpha$-SMA were increased in a dose- and time-dependent manner by BMP9 treatment (Fig. 2B and C). The results indicated that BMP9 induced HFL-1 cell transdifferentiation and increased HFL-1 cell ECM protein synthesis.

BMP9 activates Smad1/5 signaling in HFL-1 cells. In the majority of cell types, BMP9 activates Smad1/5 to regulate its biological function via ALK1, a receptor with high affinity to BMP9 (13,14). To assess whether BMP9 promoted HFL-1 cell

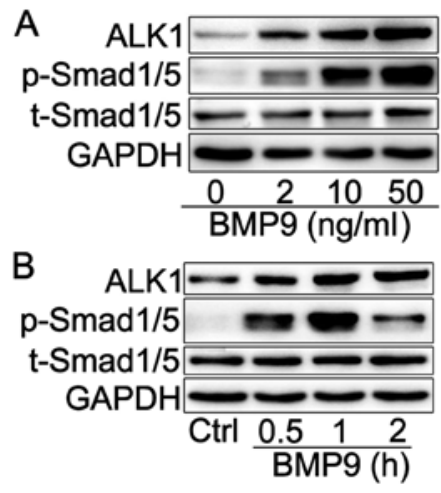

Figure 3. BMP9 activates ALK1/Smad1/5 signaling in HFL-1 cells. Effect of (A) different concentrations of BMP9 and (B) incubation with BMP9 for different time periods on the protein expression levels of ALK1, $\mathrm{p}-\mathrm{Smad} 1 / 5$ and $\mathrm{t}-\mathrm{Smad1} / 5$. BMP9, bone morphogenetic protein 9; ALK1, activin receptorlike kinase 1; p, phosphorylated; t, total; ctrl, control.

proliferation and differentiation via ALK1/Smad1/5 signaling, the expression levels of ALK1 expression and p-Smad1/5 were assessed via western blotting. BMP9 increased the expression levels of ALK1 and p-Smad1/5 in a dose-dependent manner. At $10 \mathrm{ng} / \mathrm{ml}$, BMP9 increased the expression levels of ALK1 and p-Smad1/5 in a time-dependent manner (Fig. 3B), reaching a maximal level at the $1 \mathrm{~h}$ time point. In addition, the expression level of $\mathrm{p}$-Smad1/5 decreased when HFL-1 cells were exposed to BMP9 for $2 \mathrm{~h}$ compared with $1 \mathrm{~h}$, which may be associated with the rapid turnover of p-Smad1/5 in HFL-1 cells. Lo and Massagué (33) suggested that once Smad proteins enter the nucleus, they might be degraded by ubiquitination. Therefore, the results suggested that BMP9 might trigger Smad1/5 activation via ALK1 in HFL-1 cells, which may serve as a mechanism underlying BMP9-induced HFL-1 cell activation.

ALK1 inhibitor suppresses the effects of BMP9 in HFL-1 cells. To investigate the effect of BMP9 on HFL-1 cells via ALK1/Smad1/5 signaling, the inhibitory role of Dor, an ALK1 inhibitor, on BMP9-mediated HFL-1 cell responses was assessed. Dor notably reduced BMP9-induced ALK1 and p-Smad1/5 expression levels (Fig. 4A). Dor also significantly inhibited BMP9-induced cell viability and colony formation (Fig. 4B and C). Similarly, Dor decreased BMP9-mediated upregulation of $\alpha$-SMA, collagen I and collagen III expression (Fig. 4D and E). The results further suggested that BMP9 increased HFL-1 cell proliferation and differentiation via activating ALK1/Smad1/5 signaling.

\section{Discussion}

Fibroblast activation is a major mechanism underlying the fibrotic process that occurs during pulmonary fibrosis, in which a variety of cytokines have been reported to be associated with, such as TGF- $\beta 1$ (34), BMP4 and BMP7 (35). TGF- $\beta 1$ is a profibrotic cytokine (34), whereas BMP4 displays antifibrotic properties (35). However, the effect of BMP9 on lung fibroblast activation is not completely understood. The present study suggested that BMP9 was a profibrotic regulator that displayed a key role in inducing HFL-1 cell proliferation and differentiation via Smad1/5 activation. Therefore, the 

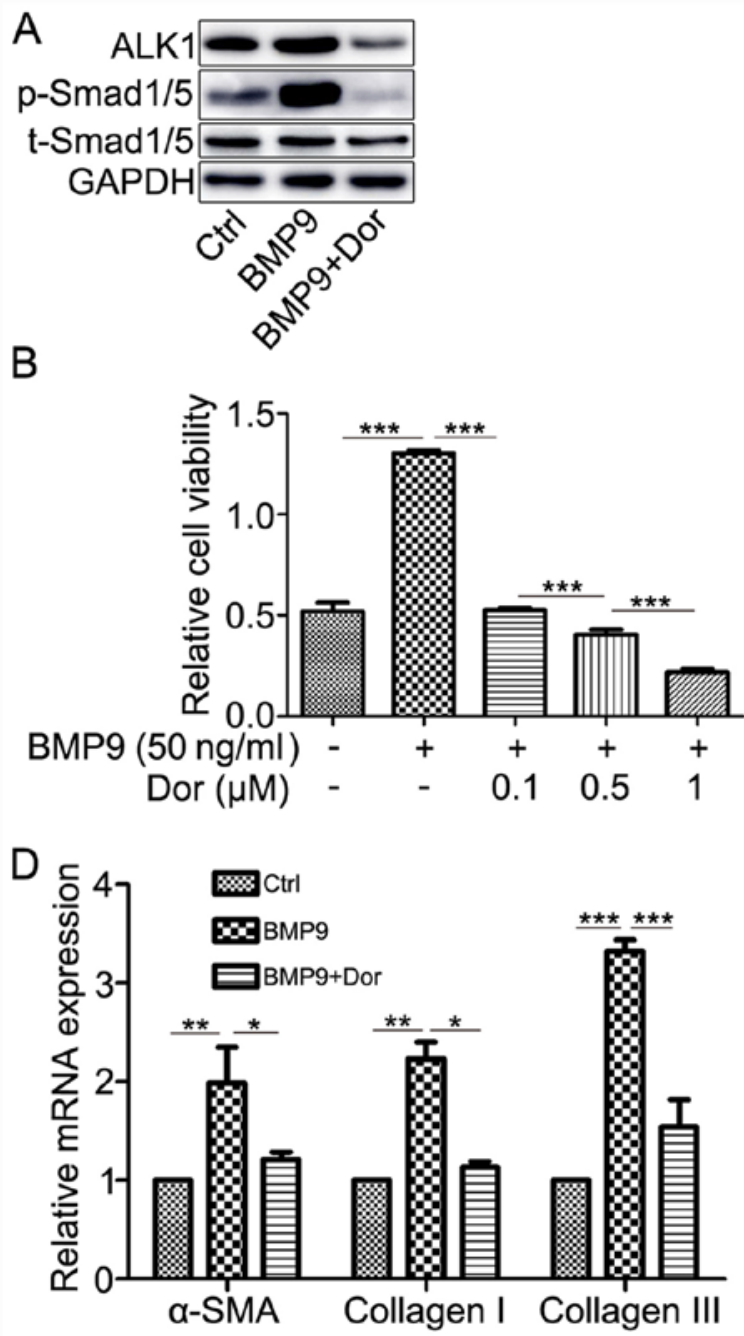
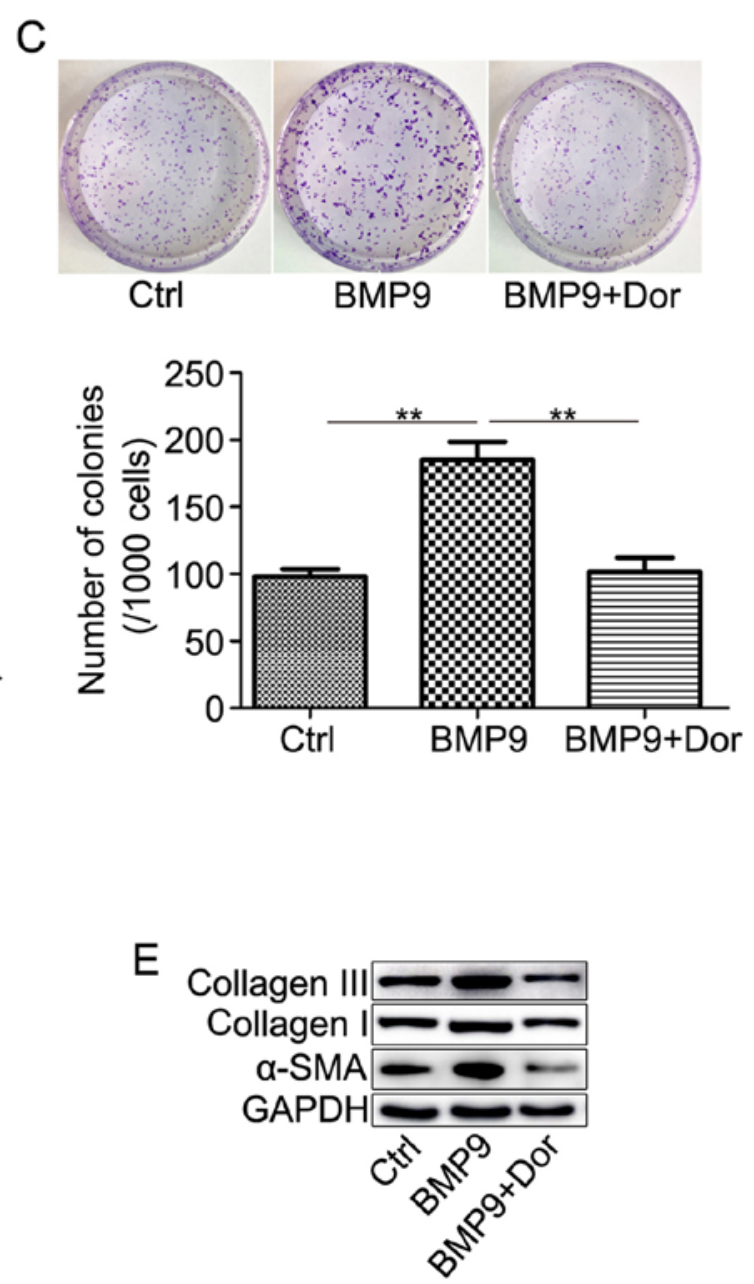

Figure 4. ALK1 inhibitor Dor suppresses the effects of BMP9 on HFL-1 cells. (A) Protein expression levels of $\alpha$-SMA, collagen I and collagen III. (B) Cell viability was detected by performing the Cell Counting Kit-8 assay. (C) Colony formation was measured by performing colony formation assays . (D) mRNA and (E) protein expression levels of $\alpha$-SMA, collagen I and collagen III. ${ }^{*} \mathrm{P}<0.05,{ }^{* *} \mathrm{P}<0.01$ and ${ }^{* * * *} \mathrm{P}<0.001$. ALK1, activin receptor-like kinase 1; Dor, dorsomorphin-1; BMP9, bone morphogenetic protein 9; $\alpha$-SMA, $\alpha$-smooth muscle actin; ctrl, control.

present study suggested a potential mechanism underlying pulmonary fibrosis and indicated that BMP9 may serve as a potential therapeutic target for fibroblast activation-associated lung diseases, such as lung fibrosis and cancer.

BMP9 is primarily synthesized in hepatic tissues, but actively circulates in the bloodstream (36), performing physiological and pathophysiological functions, such as angiogenesis (11), neuronal differentiation (12), osteogenic development (37) and carcinogenesis (38). Previous studies have indicated that BMP9 is a key regulator of fibrogenesis (22-26). For example, BMP9 promotes liver fibrosis as evidenced by rBMP9 increasing human hepatic stellate cell proliferation and migration, whereas BMP9 inhibition or knockout reduces liver fibrosis (22). By contrast, BMP9 decreases the synthesis of collagen I in cardiac fibroblasts, and loss of BMP9 activity increases cardiac fibrosis (24). Similarly to previous studies, the present study indicated that rBMP9 significantly promoted cell proliferation and induced differentiation into myofibroblasts, as evidenced by increased $\alpha$-SMA and ECM protein (collagen I and collagen III) expression levels, which were suppressed by BMP type I receptor inhibitor. Therefore, the present study supported the hypothesis that BMP9 may induce lung fibroblast activation and serve as a profibrotic cytokine during lung fibrosis. The role of BMP9 in lung fibrosis requires further investigation in an animal model of pulmonary fibrosis or in patients with pulmonary fibrosis.

Additionally, accumulating studies have demonstrated that fibroblast-type cells are a key host cell type in tumor metastasis via microenvironmental modulation, and fibroblast activation is a critical event in tumor progression and metastasis (39-42). A number of ECM proteins have been identified, including an elevated deposition of fibroblast-derived fibronectin, in the tumor microenvironment (43-45). Moreover, previous studies have indicated that the transformation of normal lung fibroblasts to a myofibroblast phenotype and the formation of cancer-associated fibroblasts promoted tumor progression in non-small cell lung cancer (46-48). Therefore, targeting cancerassociated fibroblasts is an important alternative treatment strategy for lung cancer. The present study further suggested that exogenous BMP9 activated lung fibroblasts, which indicated that BMP9 might be involved in the progression and metastasis of lung cancer via regulating cancer-associated 
fibroblasts, a process that is similar to lung fibroblast activation during pulmonary fibrosis. Meanwhile, several studies have reported that BMP signaling, including BMP receptor type II, endoglin, growth differentiation factor 15 and Smad4, is involved in tumor progression and metastasis via regulating cancer-associated fibroblasts (49-51). For example, Paauwe et al (49) demonstrated that endoglin, a coreceptor for TGF- $\beta$ and BMP9, is expressed in cancer-associated fibroblasts, and endoglin-expressing cancer-associated fibroblasts contribute to colorectal cancer progression and metastasis. Therefore, whether BMP9 is implicated in cancer-associated fibroblast metastasis requires further investigation.

As a member of the TGF- $\beta$ superfamily, BMP9 binds to type I and type II transmembrane receptors, including ALK1, ALK2, BMP receptor type II and activin receptor type IIB, to exert its effects $(17,18,27)$. Type I BMP receptor ALK1 has been identified as displaying the highest affinity with BMP9 in the majority of cell types (52). Typically, when BMP9 binds to the ALK1 receptor, it primarily activates the expression of downstream p-Smad1/5 $(17,18)$. Numerous studies have reported that $\mathrm{Smad} 1 / 5$ is activated in fibrotic diseases (20,53-55). During hepatic fibrosis, BMP9 induced the expression of inhibitor of differentiation 1 via the Smad1 signaling pathway, thereby triggering hepatic stellate cells to differentiate into myofibroblasts $(52,53)$. In addition, Li et al (20) demonstrated that the BMP9/ALK1/Smad1 signaling pathway is involved in the epithelial-mesenchymal transition of liver cancer cells, which is an important mechanism underlying hepatic fibrosis. In the cellular context of scleroderma fibroblasts, ALK1/Smad1/5 signaling promotes ECM proteins, such as collagen I and CTGF (54). Consistent with the aforementioned studies, the present study indicated that rBMP9 increased ALK1 expression and Smad1/5 phosphorylation, and promoted cell viability, colony formation and the expression of $\alpha$-SMA, collagen I and collagen III in HFL-1 cells. Moreover, the present study suggested that Dor partly rescued BMP9-induced effects. Therefore, the results supported the hypothesis that the ALK1/Smad1/5 signaling pathway might be implicated in BMP9-mediated HFL-1 cell proliferation and differentiation.

Collectively, the present study indicated that BMP9 directly induced HFL-1 cell proliferation. In addition, the results suggested that the activated ALK1/Smad1/5 signaling pathway may mediate BMP9-induced HFL-1 cell proliferation and differentiation. Moreover, the results indicated that BMP9 may serve as an activator of lung fibroblast proliferation and differentiation and may also serve as a profibrotic cytokine in pulmonary fibrosis, supporting its potential role in the treatment of lung fibrosis. Furthermore, BMP9-mediated lung fibroblast activation indicated that the potential role of BMP9-regulated cancer-associated fibroblasts during the progression and metastasis of lung cancer requires further investigation. However, the present study had a number of limitations. For example, the study focused on in vitro experiments and only HFL-1 cells were used in the study. Therefore, future studies should explore the role of BMP9 in other cell lines, in vivo or by using clinical tissue samples to identify the exact role of BMP9 in pulmonary fibrosis and evaluate the possible effect of BMP9-regulating cancer-associated fibroblasts on lung cancer.

\section{Acknowledgements}

Not applicable.

\section{Funding}

The present study was supported by the National Natural Science Foundation of China (grant nos. 81660163 and 81560299) and the National Natural Science Foundation of Jiangxi Province (grant nos. 20151BAB205002 and 20161BAB205205).

\section{Availability of data and materials}

The datasets used and/or analyzed during the present study are available from the corresponding author on reasonable request.

\section{Authors' contributions}

YW designed and performed the main experiments and analyzed the data. XS analyzed the data. YY performed the experiments and analyzed the data. $\mathrm{YH}$ contributed to designing the study. YW and $\mathrm{YH}$ can authenticate the raw data in this study. All authors read and approved the final manuscript.

\section{Ethics approval and consent to participate}

Not applicable.

\section{Patient consent for publication}

Not applicable.

\section{Competing interests}

The authors declare that they have no competing interests.

\section{References}

1. King TE Jr, Pardo A and Selman M: Idiopathic pulmonary fibrosis. Lancet 378: 1949-1961, 2011.

2. Tsubouchi K, Araya J, Minagawa S, Hara H, Ichikawa A, Saito N, Kadota T, Sato N, Yoshida M, Kurita Y, et al: Azithromycin attenuates myofibroblast differentiation and lung fibrosis development through proteasomal degradation of NOX4. Autophagy 13: 1420-1434, 2017

3. Shu DY and Lovicu FJ: Myofibroblast transdifferentiation: The dark force in ocular wound healing and fibrosis. Prog Retin Eye Res 60: 44-65, 2017

4. Meng XM, Nikolic-Paterson DJ and Lan HY: TGF- $\beta$ : The master regulator of fibrosis. Nat Rev Nephrol 12: 325-338, 2016.

5. Mody AA, Wordinger RJ and Clark AF: Role of ID proteins in BMP4 inhibition of profibrotic effects of TGF- $\beta 2$ in human TM cells. Invest Ophthalmol Vis Sci 58: 849-859, 2017.

6. Liu L, Wang Y, Yan R, Liang L, Zhou X, Liu H, Zhang X, Mao Y, Peng W, Xiao Y, et al: BMP-7 inhibits renal fibrosis in diabetic nephropathy via miR-21 downregulation. Life Sci 238: 116957-116967, 2019.

7. Xiao L, Du Y, Shen Y, He Y, Zhao H and Li Z: TGF-beta 1 induced fibroblast proliferation is mediated by the FGF-2/ERK pathway. Front Biosci 17: 2667-2674, 2012.

8. Miller AF, Harvey SA, Thies RS and Olson MS: Bone morphogenetic protein-9. An autocrine/paracrine cytokine in the liver. J Biol Chem 275: 17937-17945, 2000. 
9. Breitkopf-Heinlein K, Meyer C, König C, Gaitantzi H, Addante A, Thomas M, Wiercinska E, Cai C, Li Q, Wan F, et al: BMP-9 interferes with liver regeneration and promotes liver fibrosis. Gut 66: 939-954, 2017

10. Chen C, Grzegorzewski KJ, Barash S, Zhao Q, Schneider H, Wang Q, Singh M, Pukac L, Bell AC, Duan R, et al: An integrated functional genomics screening program reveals a role for BMP-9 in glucose homeostasis. Nat Biotechnol 21: 294-301, 2003.

11. Scharpfenecker M, van Dinther M, Liu Z, van Bezooijen RL, Zhao Q, Pukac L, Löwik CWGM and ten Dijke P: BMP-9 signals via ALK1 and inhibits bFGF-induced endothelial cell proliferation and VEGF-stimulated angiogenesis. J Cell Sci 120 964-972, 2007.

12. Schnitzler AC, Mellott TJ, Lopez-Coviella I, Tallini YN, Kotlikoff MI, Follettie MT and Blusztajn JK: BMP9 (bone morphogenetic protein 9) induces NGF as an autocrine/paracrine cholinergic trophic factor in developing basal forebrain neurons. J Neurosci 30: 8221-8228, 2010.

13. David L, Mallet C, Keramidas M, Lamandé N, Gasc JM, Dupuis-Girod S, Plauchu H, Feige JJ and Bailly S: Bone morphogenetic protein-9 is a circulating vascular quiescence factor. Circ Res 102: 914-922, 2008

14. Fong D, Bisson M, Laberge G, McManus S, Grenier G, Faucheux N and Roux S: Bone morphogenetic protein-9 activates Smad and ERK pathways and supports human osteoclast function and survival in vitro. Cell Signal 25: 717-728, 2013.

15. Wang J, Weng Y, Zhang M, Li Y, Fan M, Guo Y, Sun Y, Li W and Shi Q: BMP9 inhibits the growth and migration of lung adenocarcinoma A549 cells in a bone marrow stromal cell-derived microenvironment through the MAPK/ERK and NF- $\mathrm{B}$ pathways. Oncol Rep 36: 410-418, 2016.

16. Addante A, Roncero C, Almalé L, Lazcanoiturburu N, GarcíaÁlvaro M, Fernández M, Sanz J, Hammad S, Nwosu ZC, Lee SJ, et al: Bone morphogenetic protein 9 as a key regulator of liver progenitor cells in DDC-induced cholestatic liver injury. Liver Int 38: 1664-1675, 2018.

17. Mostafa S, Pakvasa M, Coalson E, Zhu A, Alverdy A, Castillo H, Fan J, Li A, Feng Y, Wu D, et al: The wonders of BMP9: From mesenchymal stem cell differentiation, angiogenesis, neurogenesis, tumorigenesis, and metabolism to regenerative medicine. Genes Dis 6: 201-223, 2019.

18. Cunha SI and Pietras K: ALK1 as an emerging target for antiangiogenic therapy of cancer. Blood 117: 6999-7006, 2011

19. Wang T, Zhang Z, Wang K, Wang J, Jiang Y, Xia J, Gou L, Liu M, Zhou L, He T, et al: Inhibitory effects of BMP9 on breast cancer cells by regulating their interaction with pre-adipocytes/ adipocytes. Oncotarget 8: 35890-35901, 2017.

20. Li Q, Gu X, Weng H, Ghafoory S, Liu Y, Feng T, Dzieran J, Li L, Ilkavets I, Kruithof-de Julio M, et al: Bone morphogenetic protein-9 induces epithelial to mesenchymal transition in hepatocellular carcinoma cells. Cancer Sci 104: 398-408, 2013.

21. Suzuki Y, Ohga N, Morishita Y, Hida K, Miyazono K and Watabe T: BMP-9 induces proliferation of multiple types of endothelial cells in vitro and in vivo. J Cell Sci 123: 1684-1692, 2010.

22. Li P, Li Y, Zhu L, Yang Z, He J, Wang L, Shang Q, Pan H, Wang H, Ma X, et al: Targeting secreted cytokine BMP9 gates the attenuation of hepatic fibrosis. Biochim Biophys Acta Mol Basis Dis 1864: 709-720, 2018

23. Muñoz-Félix JM, Cuesta C, Perretta-Tejedor N, Subileau M, López-Hernández FJ, López-Novoa JM and Martínez-Salgado C: Identification of bone morphogenetic protein 9 (BMP9) as a novel profibrotic factor in vitro. Cell Signal 28: 1252-1261, 2016

24. Morine KJ, Qiao X, York S, Natov PS, Paruchuri V, Zhang Y, Aronovitz MJ, Karas RH and Kapur NK: Bone morphogenetic protein 9 reduces cardiac fibrosis and improves cardiac function in heart failure. Circulation 138: 513-526, 2018

25. Morine KJ, Qiao X, Paruchuri V, Aronovitz MJ, Mackey EE, Buiten L, Levine J, Ughreja K, Nepali P, Blanton RM, et al: Reduced activin receptor-like kinase 1 activity promotes cardiac fibrosis in heart failure. Cardiovasc Pathol 31: 26-33, 2017.

26. Morine KJ, Qiao X, Paruchuri V, Aronovitz MJ, Mackey EE, Buiten L, Levine J, Ughreja K, Nepali P, Blanton RM, et al: Conditional knockout of activin like kinase-1 (ALK-1) leads to heart failure without maladaptive remodeling. Heart Vessels 32: 628-636, 2017.

27. Bi J and Ge S: Potential roles of BMP9 in liver fibrosis. Int J Mol Sci 15: 20656-20667, 2014
28. Chen X, Orriols M, Walther FJ, Laghmani EH, Hoogeboom AM, Hogen-Esch ACB, Hiemstra PS, Folkerts G, Goumans MTH, Ten Dijke $\mathrm{P}$, et al: Bone morphogenetic protein 9 protects against neonatal hyperoxia-induced impairment of alveolarization and pulmonary inflammation. Front Physiol 8: 486-502, 2017.

29. Wang XJ, Lian TY, Jiang X, Liu SF, Li SQ, Jiang R, Wu WH, Ye J, Cheng CY, Du Y, et al: Germline BMP9 mutation causes idiopathic pulmonary arterial hypertension. Eur Respir J 53: 1801609-1801618, 2019.

30. Livak KJ and Schmittgen TD: Analysis of relative gene expression data using real-time quantitative PCR and the 2(-Delta Delta C(T)) Method. Methods 25: 402-408, 2001.

31. Huang YH, Zhou XY, Wang HM, Xu H, Chen J and Lv NH: Aquaporin 5 promotes the proliferation and migration of human gastric carcinoma cells. Tumour Biol 34: 1743-1751, 2013.

32. Ruwanpura SM, Thomas BJ and Bardin PG: Pirfenidone: Molecular mechanisms and potential clinical applications in lung disease. Am J Respir Cell Mol Biol 62: 413-422, 2020.

33. Lo RS and Massagué J: Ubiquitin-dependent degradation of TGF- $\beta$-activated smad2. Nat Cell Biol 1: 472-478, 1999.

34. Huang LS, Jiang P, Feghali-Bostwick C, Reddy SP, Garcia JGN and Natarajan V: Lysocardiolipin acyltransferase regulates TGF- $\beta$ mediated lung fibroblast differentiation. Free Radic Biol Med 112: 162-173, 2017

35. Pegorier S, Campbell GA, Kay AB and Lloyd CM: Bone morphogenetic protein (BMP)-4 and BMP-7 regulate differentially transforming growth factor (TGF)-betal in normal human lung fibroblasts (NHLF). Respir Res 11: 85-94, 2010.

36. Tillet E, Ouarné M, Desroches-Castan A, Mallet C, Subileau M, Didier R, Lioutsko A, Belthier G, Feige JJ and Bailly S: A heterodimer formed by bone morphogenetic protein 9 (BMP9) and BMP10 provides most BMP biological activity in plasma. J Biol Chem 293: 10963-10974, 2018.

37. Liao J, Yu X, Hu X, Fan J, Wang J, Zhang Z, Zhao C, Zeng Z, Shu Y, Zhang R, et al: lncRNA H19 mediates BMP9-induced osteogenic differentiation of mesenchymal stem cells (MSCs) through Notch signaling. Oncotarget 8: 53581-53601, 2017.

38. Ouarné M, Bouvard C, Boneva G, Mallet C, Ribeiro J, Desroches-Castan A, Soleilhac E, Tillet E, Peyruchaud O and Bailly S: BMP9, but not BMP10, acts as a quiescence factor on tumor growth, vessel normalization and metastasis in a mouse model of breast cancer. J Exp Clin Cancer Res 37: 209-218, 2018.

39. Strell C, Rundqvist H and Ostman A: Fibroblasts - a key host cell type in tumor initiation, progression, and metastasis. Ups J Med Sci 117: 187-195, 2012.

40. Chen X and Song E: Turning foes to friends: Targeting cancerassociated fibroblasts. Nat Rev Drug Discov 18: 99-115, 2019.

41. Affo S, Yu LX and Schwabe RF: The role of cancer-associated fibroblasts and fibrosis in liver cancer. Annu Rev Pathol 12: 153-186, 2017.

42. Richards KE, Zeleniak AE, Fishel ML, Wu J, Littlepage LE and Hill R: Cancer-associated fibroblast exosomes regulate survival and proliferation of pancreatic cancer cells. Oncogene 36: 1770-1778, 2017.

43. Najafi M, Farhood B and Mortezaee K: Extracellular matrix (ECM) stiffness and degradation as cancer drivers. J Cell Biochem 120: 2782-2790, 2019.

44. Paolillo $\mathrm{M}$ and Schinelli S: Extracellular matrix alterations in metastatic processes. Int J Mol Sci 20: 4947-4956, 2019.

45. Erdogan B, Ao M, White LM, Means AL, Brewer BM, Yang L, Washington MK, Shi C, Franco OE, Weaver AM, et al: Cancerassociated fibroblasts promote directional cancer cell migration by aligning fibronectin. J Cell Biol 216: 3799-3816, 2017.

46. Li F, Zhao S, Cui Y, Guo T, Qiang J, Xie Q, Yu W, Guo W, Deng W, Gu C, et al: a1,6-Fucosyltransferase (FUT8) regulates the cancer-promoting capacity of cancer-associated fibroblasts (CAFs) by modifying EGFR core fucosylation (CF) in non-small cell lung cancer (NSCLC). Am J Cancer Res 10: 816-837, 2020.

47. Luo M, Luo Y, Mao N, Huang G, Teng C, Wang H, Wu J, Liao X and Yang J: Cancer-associated fibroblasts accelerate malignant progression of non-small cell lung cancer via connexin 43-formed unidirectional gap junctional intercellular communication. Cell Physiol Biochem 51: 315-336, 2018.

48. Li H, Zhang Q, Wu Q, Cui Y, Zhu H, Fang M, Zhou X, Sun Z and Yu J: Interleukin-22 secreted by cancer-associated fibroblasts regulates the proliferation and metastasis of lung cancer cells via the PI3K-Akt-mTOR signaling pathway. Am J Transl Res 11: 4077-4088, 2019 . 
49. Paauwe M, Schoonderwoerd MJA, Helderman RFCP, Harryvan TJ, Groenewoud A, van Pelt GW, Bor R, Hemmer DM, Versteeg HH, Snaar-Jagalska BE, et al: Endoglin expression on cancer-associated fibroblasts regulates invasion and stimulates colorectal cancer metastasis. Clin Cancer Res 24: 6331-6344, 2018.

50. Pickup MW, Hover LD, Polikowsky ER, Chytil A, Gorska AE, Novitskiy SV, Moses HL and Owens P: BMPR2 loss in fibroblasts promotes mammary carcinoma metastasis via increased inflammation. Mol Oncol 9: 179-191, 2015.

51. Bruzzese F, Hägglöf C, Leone A, Sjöberg E, Roca MS Kiflemariam S, Sjöblom T, Hammarsten P, Egevad L, Bergh A, et al: Local and systemic protumorigenic effects of cancer-associated fibroblast-derived GDF15. Cancer Res 74: 3408-3417, 2014

52. David L, Mallet C, Mazerbourg S, Feige JJ and Bailly S: Identification of BMP9 and BMP10 as functional activators of the orphan activin receptor-like kinase 1 (ALK1) in endothelial cells. Blood 109: 1953-1961, 2007.
53. Shen H, Fan J, Burczynski F, Minuk GY, Cattini P and Gong Y: Increased Smad1 expression and transcriptional activity enhances trans-differentiation of hepatic stellate cells. J Cell Physiol 212: 764-770, 2007.

54. Wang CY, Xiao X, Bayer A, Xu Y, Dev S, Canali S, Nair AV, Masia R and Babitt JL: Ablation of hepatocyte Smad1, Smad5, and Smad8 causes severe tissue iron loading and liver fibrosis in mice. Hepatology 70: 1986-2002, 2019.

55. Pannu J, Asano Y, Nakerakanti S, Smith E, Jablonska S, Blaszczyk M, ten Dijke P and Trojanowska M: Smad1 pathway is activated in systemic sclerosis fibroblasts and is targeted by imatinib mesylate. Arthritis Rheum 58: 2528-2537, 2008.

This work is licensed under a Creative Commons Attribution-NonCommercial-NoDerivatives 4.0 International (CC BY-NC-ND 4.0) License. 